\title{
Congenital Hypopituitarism: Various Genes, Various Phenotypes
}

Authors

Maria Xatzipsalti1, 2, Antonis Voutetakis ${ }^{1}$, Lela Stamoyannou², George P. Chrousos ${ }^{1}$, Christina Kanaka-Gantenbein ${ }^{1}$

Affiliations

1 Division of Endocrinology, Diabetes and Metabolism, First Department of Pediatrics, Medical School, National and Kapodistrian University of Athens, "Aghia Sofia” Children's Hospital, Athens, Greece

2 First Department of Pediatrics, "Aglaia Kyriakou" Children's Hospital, Athens, Greece

\section{Key words}

pituitary, combined pituitary hormone deficiency, congenital hypopituitarism, transcription factors, syndromic hypopituitarism, non-syndromic hypopituitarism

$\begin{array}{ll}\text { received } & 27.03 .2018 \\ \text { accepted } & 10.12 .2018\end{array}$

Bibliography

DOI https://doi.org/10.1055/a-0822-3637

Horm Metab Res 2019; 51: 81-90

(c) Georg Thieme Verlag KG Stuttgart · New York

ISSN 0018-5043

Correspondence

Maria Xatzipsalti, MD, PhD

Consultant in Pediatrics

First Department of Pediatrics

“Aglaia Kyriakou” Children's Hospital

Athens

Greece

Tel.: + 30/213/2009 352, Fax: + 30/210/7774 127

mxatzipsalti@yahoo.gr

\section{ABSTRACT}

The ontogenesis and development of the pituitary gland is a highly complex process that depends on a cascade of transcription factors and signaling molecules. Spontaneous mutations and transgenic murine models have demonstrated a role for many of these factors, including HESX1, PROP1, PIT1, LHX3, LHX4, SOX2, SOX3, OTX2, PAX6, FGFR1, SHH, GLI2, and FGF8 in the etiology of congenital hypopituitarism. Genetic mutations in any of these factors can lead to congenital hypopituitarism, which is characterized by the deficiency in one or more pituitary hormones. The phenotype can be highly variable, consisting of isolated hypopituitarism or more complex disorders. The same phenotype can be attributed to different gene mutations; while a given gene mutation can induce different phenotypes. This review highlights the genetic variations that lead to congenital hypopituitarism and their associated defects. The overall incidence of mutations in known transcription factors in patients with hypopituitarism is low; therefore many gene mutations or even gene- epigenetic interactions have to be unraveled in the future to explain the vast majority of still unclear cases of congenital hypopituitarism.

\section{Introduction}

The pituitary gland is the "maestro" of the body's endocrine axes by regulating the secretion of most hormones from the other endocrine organs. The mature pituitary gland consists of the adenohypophysis (anterior and intermediate lobes) and the neurohypophysis or posterior lobe. The anterior pituitary consists of 5 distinct cell types producing 6 different hormones: somatotrophs, producing growth hormone $(\mathrm{GH})$, thyrotrophs, producing thyroid stimulating hormone (TSH), lactotrophs, producing prolactin (PRL), gonadotrophs, producing follicle-stimulating hormone (FSH) and luteinizing hormone (LH) and corticotrophs, producing adrenocorticotrophic hormone (ACTH). The intermediate lobe secretes pro-opiomelano- cortin (POMC) which is the precursor of the melanocyte-stimulating hormone (MSH) and endorphins. The posterior lobe is responsible for storing and secreting antidiuretic hormone (ADH) and oxytocin, which are produced in the paraventricular and supraoptic nuclei of the hypothalamus.

The ontogenesis of the pituitary gland is a highly complex process that results from the interaction of transcription factors and signaling molecules. Congenital hypopituitarism is characterized by the deficiency in one, or more pituitary hormones. In some patients pituitary hormonal deficiencies may present as a part of a syndrome. 


\section{Embryology of the Pituitary Gland (Based on Murine Models)}

Human pituitary development is similar to the murine pituitary development and most of our knowledge is based on the murine animal model. The anterior and intermediate lobes are derived from the oral ectoderm, while the posterior pituitary is derived from the neural ectoderm of the ventral diencephalon. Its development occurs in 4 stages: (i) the pituitary placode, (ii) the rudimentary Rathke's pouch, (iii) the definitive Rathke's pouch and (iv) the mature pituitary gland. The placode appears ventrally in the midline of the anterior neural ridge at embryonic (E) day 7.5 giving rise to the roof of the oral cavity. The pituitary organogenesis starts with a thickening in this roof at E 8.5, corresponding to 4-6 weeks' gestation in humans. At E9.0 it invaginates dorsally to form the rudimentary Rathke's pouch. Rudimentary Rathke's pouch deepens and folds in itself until it closes, forming the definite Rathke's pouch at E11.5. The anterior and intermediate lobes are derived from Rathke's pouch while the evagination of the posterior part of the presumptive diencephalon will give rise to the posterior pituitary. The pouch epithelium continues to proliferate between E10.5 and E12 and separates from the underlying oral ectoderm at E12.5. The progenitors of the hormone-secreting cell types proliferate ventrally from the pouch between E12.5 and 17.5 to populate the future anterior lobe [1] ( Fig. 1).

\section{Syndromic Hypopituitarism}

In this section cases of congenital hypopituitarism in the context of specific syndromes will be presented, as also summarized in - Table 1.

\section{Hypopituitarism with skeletal abnormalities (LHX3)}

LHX3, a member of the LIM class of homeodomain proteins is expressed early during anterior pituitary development, within RP at E9.5 as well as in the ventral hindbrain and spinal cord. Its expression, which persists in the mature pituitary gland, is essential for the formation of gonadotrophs, thyrotrophs, somatotrophs, and lactotrophs. In humans, 14 homozygous [2-10] , or compound heterozygous for 2 LHX3 mutations [11] and a heterozygous variant [12] have been reported so far. People with LHX3 mutations present with $\mathrm{GH}, \mathrm{TSH}$ and $\mathrm{FSH} / \mathrm{LH}$ deficiencies while ACTH deficiency is reported in $50 \%$ of the mutations. MRI images reveal different anomalies, as aplasia or hypoplasia of pituitary, a hypointensity resembling microadenoma [4] and enlargement with hyperintense signal [7]. In $10 \%$ of the cases MRI may be normal. Mutations that affect the carboxyl terminus of LHX3 proteins present with phenotypes of pituitary dysfunction only, while mutations affecting the entire gene or protein, the LIM domains or the homeodomain present with syndromes involving besides the endocrine also the nervous and skeletal systems. Extra-pituitary phenotype can include short neck with abnormal head and neck rotation (70\% of cases), vertebral abnormalities ( $50 \%$ of cases), as rigid cervical spine, flattened lumbar vertebrae, thoracic kyphosis, progressive scoliosis and mild to severe hearing defect (50\% of cases), due to the expression of LHX3 in defined regions of the sensory epithelium of the developing inner ear, which is known to be required for inner ear development. In $38 \%$ of the cases mental/learning deficiencies are reported. Two of the reported patients had also respiratory distress $[11,13]$. Heterozygous family members are unaffected.

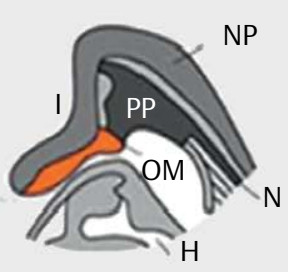

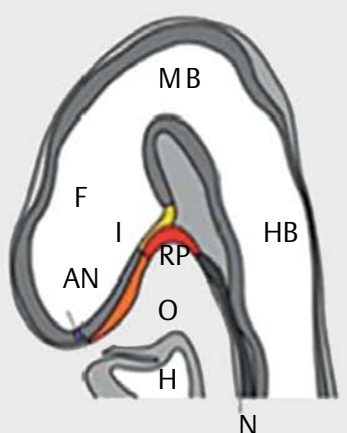

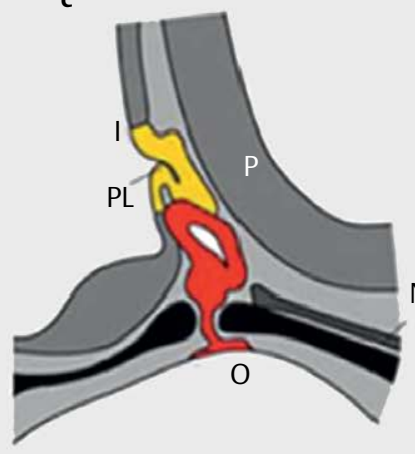

\section{Rudimentary pouch}

11

9.5
Definite pouch
14.5

12

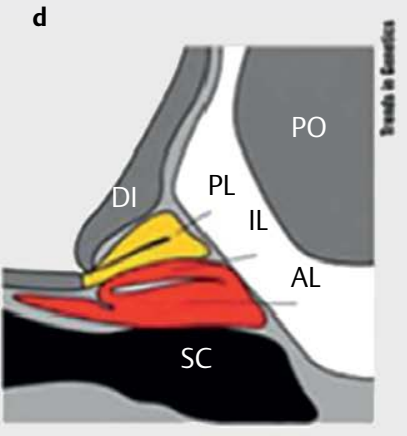

Pituitary gland
19.5

17

Embryonic

days

- Fig. 1 Stages of rodent pituitary development. a Oral ectoderm, b Rudimentary pouch; c Definitive pouch; d Adult pituitary gland. I: Infundibulum; NP: Neural plate; N: Notochord; PP: Pituitary placode; OM: Oral membrane; H: Heart; F: Forebrain; MB: Midbrain; HB: Hindbrain; RP: Rathke's pouch; AN: Anterior neuralpore; O: Oral cavity; PL: Posterior lobe; OC: Optic chiasm; P: Pontine flexure; PO: Pons; IL: Intermediate lobe; AL: Anterior lobe; DI: Diencephalon; SC: Sphenoid cartilage. Source: Sheng and Westphal (Trends Genet 1999; 15: 236-240) with permission (licence number: 4230341362009). [rerif]. 
- Table 1 Gene mutations leading to congenital hypopituitarism and the associated phenotypes.

\begin{tabular}{|c|c|c|c|}
\hline $\begin{array}{l}\text { Transcrip- } \\
\text { tion factor }\end{array}$ & Transmission & $\begin{array}{l}\text { Pituitary hormone } \\
\text { deficiencies }\end{array}$ & Phenotype \\
\hline LHX3 & AR & $\begin{array}{l}\text { GH, TSH and FSH/ } \\
\mathrm{LH}, \mathrm{ACTH}(53 \%)\end{array}$ & $\begin{array}{l}\text { Abnormal head and neck rotation ( } 70 \%) \text {, vertebral abnormalities ( } 50 \%) \text {, mild to } \\
\text { severe hearing defect, pituitary hypo- or hyperplasia }\end{array}$ \\
\hline LHX4 & $A D$ & IGHD or CPHD & $\begin{array}{l}\text { Pituitary hypoplasia, ectopic posterior pituitary and small sella turcica, corpus } \\
\text { callosum hypoplasia or Chiari syndrome. Respiratory distress }\end{array}$ \\
\hline HESX1 & $\mathrm{AD} / \mathrm{AR}$ & IGHD or CPHD & SOD, hypoplastic or aplastic anterior pituitary, corpus callosum hypoplasia \\
\hline SOX2 & AR & $\begin{array}{l}\text { LH, FSH, variable } \\
\text { GHD }\end{array}$ & Microphthalmia, mental retardation, sensorineural hearing loss, esophageal atresia \\
\hline SOX3 & X-linked & IGHD or CPHD & $\begin{array}{l}\text { Anterior pituitary hypoplasia, absent pituitary stalk, ectopic neurohypophysis, } \\
\text { intellectual disability }\end{array}$ \\
\hline OTX2 & $A D$ & IGHD or CPHD & $\begin{array}{l}\text { Eye malformations, normal or hypoplastic anterior pituitary, normal or ectopic } \\
\text { posterior pituitary, Chiari syndrome }\end{array}$ \\
\hline PAX6 & AR & $\begin{array}{l}\text { GH, ACTH (?), } \\
\text { FSH,LH }\end{array}$ & Eye malformations, pituitary hypoplasia \\
\hline BMP4 & AR & CPHD & $\begin{array}{l}\text { Ocular malformations, sensorineural deafness, developmental delay, spondyloepi- } \\
\text { physeal dysplasia tarda, cerebellar, pituitary abnormalities, partial callosal agenesis }\end{array}$ \\
\hline ARNT2 & AR & $\mathrm{Cl}, \mathrm{CPHD}$ & $\begin{array}{l}\text { Eye anomalies, hypoplastic anterior pituitary and thin pituitary stalk, microcephaly, } \\
\text { renal anomalies }\end{array}$ \\
\hline FGF8 & $\mathrm{AD} / \mathrm{AR}$ & $\begin{array}{l}\text { LH, FSH, TSH, ACTH, } \\
\text { DI }\end{array}$ & $\begin{array}{l}\text { Semilobar HPE, diabetes insipidus, absent corpus callosum, hypoplastic optic nerves, } \\
\text { Moebius syndrome }\end{array}$ \\
\hline FGFR1 & $A D$ & CPHD & Absent corpus callosum, septo-optic dysplasia and midline defects \\
\hline $\mathrm{SHH}$ & AR & CPHD, DI & Midline cerebral defects, holoprosencephaly (HPE) \\
\hline GII2 & haploinsufficiency & CPHD & HPE, polydactyly, midline defects, ectopic pituitary lobe \\
\hline PROKR2 & $A R / A D$ & $\mathrm{FSH}, \mathrm{LH}$ & PSIS, corpus callosum hypoplasia, optic nerve anomalies, $\mathrm{Cl}$ \\
\hline GPR161 & AR & $\mathrm{GH}$ & $\begin{array}{l}\text { PSIS, anterior pituitary hypoplasia, ectopic posterior pituitary, empty sella, } \\
\text { congenital alopecia }\end{array}$ \\
\hline IGSF1 & X-linked & TSH, GH, PRL & Macro-orchidism, delayed adrenarche \\
\hline Pix2 & $\mathrm{AD} / \mathrm{AR}$ & & Axenfeld-Rieger syndrome \\
\hline NFKB2 & $A D$ & ACTH, GH, TSH & Immune deficiency \\
\hline CHD7 & $A D$ & GH, TSH, FSH, LH & CHARGE syndrome, ectopic posterior pituitary \\
\hline Pit1/POU1F1 & $\mathrm{AD} / \mathrm{AR}$ & GH, TSH, PRL & Pituitary hypoplasia \\
\hline Prop1 & AR & $\begin{array}{l}\text { GH, TSH, PRL, LH, } \\
\text { FSH, evolving ACTH }\end{array}$ & Pituitary hypoplasia or transient hyperplasia \\
\hline
\end{tabular}

\section{Hypopituitarism with cerebellar abnormalities and/or lung defects (LHX4)}

Closely related to LHX3 is LHX4, which can be detected in Rathke's pouch at E9.5 and in the anterior part of the pituitary at E12.5. LHX4 mutations result in the formation of a hypoplastic pituitary, containing all differentiated cell types but in reduced numbers. A lack of proliferation in Lhx4 mutants causes failure to respond to inductive signals and subsequent dysregulation of other transcription factor genes, for example, Lhx3, inevitably leading to increased cell death [14]. In humans, 15 sporadic or familiar LHX4 mutations have been reported with variable hypopituitarism (ranging from isolat- ed GH deficiency to complete panhypopituitarism) [15] and brain abnormalities (pituitary hypoplasia, ectopic posterior pituitary and poorly developed sella turcica as well as corpus callosum hypoplasia or Chiari syndrome) [12,16-19]. Of note, 4 patients also presented respiratory distress [20-22] and one presented heart defect [21]. A recent reported homozygous mutation has been associated with a lethal phenotype (severe panhypopituitarism associated with pituitary aplasia and posterior ectopia, mild facial hypoplasia, undescended testes and respiratory distress) [22]. In a very large cohort of 417 unrelated patients with hypopituitarism the prevalence of LHX4 mutations was $1.4 \%$ [23]. 


\section{Septo-optic dysplasia and other eye abnormalities}

Septo-optic dysplasia (SOD) is defined by the presence of at least 2 of the following: (i) optic nerve hypoplasia (ONH), (ii) midline forebrain defects and (iii) pituitary hypoplasia Rarely, the eye abnormalities may be more severe including anophthalmia or severe microphthalmia. Neurological manifestations are common and range from focal deficits to global developmental delay. Mutations in HESX1, SOX2, SOX3, OTX2 have all been implicated in the etiology of SOD.

HESX1, a member of the paired-like class of homeobox genescan be detected in the anterior forebrain from E7.5 to E8.5 and in the Rathke's pouch from E8.5 to E13.5, after which period it is rapidly down regulated. It regulates the expression of other genes such as PROP1, suggesting that both function as opposing transcription factors. Initial activation of HEX1 is dependent upon LHX1 and LHX3. Mice homozygous for Hesx1 present with anophthalmia or microphthalmia and midline neurological defects (e. g., absent septum pellucidum and pituitary hypoplasia), reminiscent of SOD. The first homozygous missense mutation [24] was detected in 2 siblings born to consanguineous parents with SOD, agenesis of the corpus callosum, optic nerve hypoplasia, a hypoplastic anterior pituitary gland and complete panhypopituitarism. To date, several homozygous and heterozygous HESX1 mutations have been reported with variable phenotypes ranging from IGHD to CPHD associated in some cases with anomalies such as SOD and pituitary malformations [25-30]. MRI also reveals variable abnormalities, as hypoplastic or aplastic anterior pituitary and ectopic posterior pituitary. The patients carrying mutations at the heterozygous state generally show a milder phenotype than the homozygous patients. Most cases are sporadic.

SOX2 and SOX3 are members of the SOX (SRY-related high mobility group box) family of transcription factors.

SOX2 is expressed within the Rathke's pouch at 4.5-9 weeks of pituitary development and maintained throughout the anterior pituitary development as well as in the diencephalon. It plays critical role in normal development of the brain and the pituitary gland in addition to that of the eyes and inner ear. In humans, SOX2 variants have been observed in 14 patients with hypogonadotropic hypogonadism, bilateral microphthalmia, small corpus callosum, hippocampal abnormalities and inconstant mental retardation [31-35]. Pituitary phenotype usually includes inconstant $\mathrm{GH}$ [36], TSH or ACTH deficiencies. On MRI of the hypothalamus-pituitary region, morphologic anomalies include hippocampal abnormalities, hypoplasia of the corpus callosum, hypothalamic hamartomata and pituitary tumors [37]. All reported patients demonstrated learning difficulties, 4 of them had marked motor deficits and one had evidence of sensorineural deafness. Extra-pituitary anomalies included esophageal atresia.

SOX3, located on Xp27.1 is expressed throughout the central nervous system, particularly in the ventral diencephalon. SOX3 contains a DNA-binding domain conserved among SOX proteins, a short $\mathrm{N}$-terminal domain, and a longer C-terminal domain containing 4 polyalanine (PA) tracts shown to be involved in transcriptional activation. SOX3 dosage is critical for normal hypothalamic-pituitary development, and both duplications and loss of function PA expansions can lead to variable hypopituitarism. Patients with duplication of SOX3 present with IGHD without the involvement of additional adenohypophyseal hormones, more frequently with respect to patients with SOX3 sequence variants [38]. Anterior pituitary hypoplasia, an absent pituitary stalk, and ectopic neurohypophysis are other findings due to SOX3 sequence variants or whole gene deletions/duplications. Intellectual disability is frequently reported in these patients. The degree of mental retardation and the characteristics vary among patients $[39,40]$.

Orthodenticle homeobox 2 (OTX2) is a transcription factor gene that plays a critical role in brain and ocular development. OTX2 is expressed from E10.5 to E14.5 in the ventral diencephalon, where it likely interacts with HESX1 and from E10.5 to E12.5 in Rathke's pouch. OTX2 regulates various transcription factors including $\mathrm{RX} 1$, PAX6, SIX3, LHX2, MITF, GBX2, and HESX1 in order to coordinate cell determination and differentiation. In humans, 21 heterozygous de novo OTX2 mutations and one microdeletion [41] have been reported [42-45] in patients with structural eye malformations (microphthalmia, anophthalmia, underdeveloped left optic nerve, ocular coloboma) and congenital hypopituitarism. Patients present with variable hypopituitarism [46-48] with $\mathrm{GH}$ - the most vulnerable pituitary hormone- deficiency and variable brain abnormalities (MRI findings range from normal or hypoplastic anterior pituitary, normal or ectopic posterior pituitary and Chiari malformation). As OTX2 plays a key role in retinal development some of the patients with OTX2 mutations and pituitary deficiencies present also with a variety of structural eye malformations (microphthalmia, anophthalmia, underdeveloped left optic nerve, ocular coloboma). All but 3 mutations induced a loss of function in the GNRH1, HESX1, POU1F1, and IRBP (interstitial retinoid-binding protein) gene promoters, while the others are responsible for dominant negative effect $[42,49]$. No genotype-phenotype correlations exist in the reported patients.

PAX6 is a well-known key regulator gene of eye development, and its heterozygous mutations in humans cause congenital eye anomalies. PAX6 is an early dorsal marker of early anterior pituitary gland, and its expression determines the boundaries of somatotrope, lactotrope, and thyrotrope cell types [50]. Recently, 3 papers have been published, reporting that PAX6 mutations may be associated with impaired pituitary function. Hergott et al. reported corticotrope deficiency in 5 PAX6 mutation carriers [51]. Shimo et al. reported one case of PAX6 mutation with subtle hypogonadotropic hypogonadism and borderline $\mathrm{GH}$ deficiency [52] and Takagi et al. [53] identified PAX6 anomalies in 2 patients with $\mathrm{GH}$ deficiency. They both had GH deficiency and pituitary hypoplasia while the first one had also bilateral cryptorchidism, reminiscent of hypogonadism.

Bone morphogenetic protein 4 (BMP4) plays a critical role in pituitary gland development. . It is required for RP formation and maintenance and is expressed in the optic vehicle, in the diencephalic floor, consistent with its role in pituitary development and in the medial ganglionic eminence and in developing limbs [54]. Screening of 215 individuals with ocular malformations identified a chromosomal deletion of 14q22-q23 encompassing BMP4 in a familial case of anophthalmia, retinal dystrophy, brain malformation, and poly/syndactyly [54]. Deletions in BMP4 presented with bilateral anophthalmia/microphthalmia, associated with hypothyroidism, 
cryptorchidism, partial agenesis of corpus callosum, sensorineural deafness, developmental delay, and cerebellar and pituitary abnormalities. Although OTX2 has been identified within this region, it cannot explain the reported complex phenotype. Another study of 19 patients with CPHD genetic analysis of BMP4 gene revealed missense mutation in a patient presenting with skeletal abnormalities (spondyloepiphyseal dysplasia tarda) [55].

FGF receptor 1 (FGFR 1 ) is a tyrosine kinase receptor that acts as cell-surface receptor for FGF and is essential for regulation of embryonic development. It is the main receptor mediating FGF8 signaling. Genetic defects in FGFR1 have been detected in patients with CPHD [56], absent corpus callosum, septo-optic dysplasia and midline defects [57]. Recently, a Japanese female patient with CPHD and FGFR1 haplo insufficiency was described. She presented with a combined deficiency of $\mathrm{GH}$, LH and FSH, central hypothyroidism and multiple neurological abnormalities. The phenotype of this patient suggests that FGFR 1 abnormalities can be associated with various developmental defects of the anterior midline in the forebrain [58].

Aryl hydrocarbon receptor nuclear translocator 2 (ARNT2) is a member of the basic HLH-PAS (Per-ARNT-Sim homology) subfamily of transcription factors. Its precise roles during pituitary and brain development are poorly known. In the mouse, Arnt2 is expressed in hypothalamus, neural retina kidney and urinary tract in a way similar to that observed in humans. In humans its involvement in pituitary hormone secretion was identified through exome sequencing in a large consanguineous Saudi Arabian family. The 6 children presented shortly after birth with central diabetes insipidus and corticotroph deficiency; 4 had TSH deficiency, 2 had GH deficiency and one had gonadotroph deficiency with undescended testes. Brain MRI showed pituitary and extra-pituitary anomalies: hypoplastic anterior pituitary, thin pituitary stalk, hypoplastic frontal and temporal lobes, thin corpus callosum, and a global delay in brain myelination; a lack of pupil response to light was reported with post-retinal eye anomalies. All children were dysmorphic with a microcephaly, prominent forehead, deep-set eyes, a well-grooved philtrum, and retrognathia. Hydronephrosis, vesico-ureteral reflux and neurogenic bladder were also present. All children carried a homozygous c.1373_1374dupTC ARNT2 variant [59].

\section{Holoprosencephaly}

Holoprosencephaly (HPE)is a cephalic disorder in which the forebrain fails to develop in 2 hemispheres. Its etiology is multifactorial, caused by environmental or genetic factors. Specific gene mutations been recognized in only $5-10 \%$ of cases. $\mathrm{SHH}$ is expressed in the ventral diencephalon and in the adjacent oral ectoderm but not in Rathke's pouch; however, it is required for midline formation, forebrain development, brain lobe determination, eye formation and BMP2 expression induction. Disruption of $\mathrm{SHH}$ secretion and signaling during central nervous system development are one of the main causes of HPE. The clinical phenotype is highly variable ranging from closely spaced eyes or a single central maxillary incisor, to the extreme of a single cyclopic eye and superiorly placed proboscis. SHH mutations or variants are a common cause of congenital hypopituitarism in patients with usually complex midline cerebral defects [60]. SHH binds to its receptor, leading to the ac- tivation/repression of target genes via the GLI family of zinc finger transcription, such as GLI1, GII2 and GLI.3with GLI1, GII2 being most important.

Gli2 is expressed in the ventral diencephalon, where it induces BMP4 and FGF8 expression, and is also expressed in the oral ectoderm, where it induces pituitary progenitors. GLI2 mutations are associated with HPE or HPE-like features with pituitary abnormalities and polydactyl [61-63]. Patients with GLI2 sequence variants have been reported to have craniofacial anomalies ranging from severe midline defects to absence of clinical findings in mutational carriers $[64,65]$. In some patients, these findings associated with hypopituitarism [66], although polydactyly is a frequently observed concomitant abnormality [61]. After an extensive review of more than 400 patients. Bear et al. [63] concluded that HPE resulting from pathogenic GLI2 mutations is rare and these individuals present with pituitary anomalies, polydactyly and facial defects (midface hypoplasia, cleft lip/palate and hypotelorism). Among 284 patients with hypopituitarism from 3 cohorts in whom the complete coding region of GLI2 was sequenced, 15 patients (5\%) had either loss-of-function or non-synonymous GLI2 variants found in updated databases $[60,66]$ Three GLI2 mutations were recently described in patients with hypopituitarism, ectopic pituitary lobe and an absence of HPE [65].

FGF8 is important in setting up and maintaining the midbrain/ hindbrain. It is expressed in the ventral diencephalon. Mutations in this gene were only recently described in patients with phenotypes associated with congenital hypopituitarism. [67]. A female patient with homozygous mutation presented with semilobar HPE, diabetes insipidus, TSH and ACTH insufficiency and another with heterozygous mutation with an absent corpus callosum, hypoplastic optic nerves, and Moebius syndrome.

\section{Pituitary stalk interruption syndrome (PSIS)}

PSIS is a congenital defect of the pituitary gland characterized by the triad of a thin pituitary stalk, an ectopic posterior pituitary gland and hypoplasia or aplasia of the anterior pituitary gland identified by MRI. Patients with PSIS may present with either IGHD or CPHD. Over the last decade, mutations and/or single nucleotide variants in HESX1, LHX4, OTX2, SOX3, and PROKR2 have been associated with PSIS [68-70]. LHX4 mutations have been reported to cause CPHD with variable neuroradiological abnormalities: pituitary hypoplasia, ectopic posterior pituitary and small sella turcica, corpus callosum hypoplasia or Chiari syndrome.

OTX2 gene defects were also reported in 3 PSIS patients with no ocular abnormalities $[41,45]$. SOX3 may be associated with X-linked hypopituitarism, PSIS, with or without mental retardation [39]. Mutations in prokineticin-2 (PROK2) or its receptor are also implicated in PSIS. PROKR2 is a G protein-coupled receptor involved in sexual and olfactory bulb development in mice, and necessary for proper neuronal migration and angiogenesis.

Human mutations of PROK2 have been reported in isolated hypogonadotropic hypogonadism. Three heterozygous PROKR2 variants have been reported in 72 patients with PSIS [69] and 9 others in patients with variable phenotype from hypogonadotropic hypo- 
gonadism associated with SOD to panhypopituitarism; some of them had corpus callosum hypoplasia and optic nerve anomalies, and one of these patients presented with central diabetes insipidus $[57,71,72]$.

Recently, 2 female siblings with short stature due to GH deficiency, anterior pituitary hypoplasia and ectopic posterior pituitary and empty sella were reported carrying a homozygous missense mutation L19Q in GPR161[73]. Both sisters had also anatomical anomalies with a short 5 th finger, congenital alopecia, and ptosis of the left eye. GPR161 is an orphan member of the G protein-coupled receptors' family and was first described in a mutant mouse presenting with congenital cataract and neural tube defects. GPR161 is widely expressed in the early stages of embryo development including the neural folds, the pituitary and the hypothalamus in both mouse and human. GPR161 is a key negative regulator of Sonic hedgehog (Shh) pathway the pituitary target of which is GLI2. This would suggest that gain-of-function mutations of GPR161 could lead to abnormal pituitary development by repressing the Shh pathway.

Furthermore, Dakou-Voutetakis et al identified 2 novel mutations in the HPE-related genes (TGIF gene and SHH gene) in 2 patients with PSIS and a single central incisor [68].

\section{Central hypothyroidism and macro-orchidism}

IGSF1 gene located in Xq26 is expressed in Rathke's pouch, in adult pituitary gland and the testis, whereas ICSF1 protein is detected in $\mathrm{GH}$, prolactin and TSH-secreting cells. Loss of function mutations or deletions of the IGSF1 gene causes an X-linked syndrome, characterized in males by congenital central hypothyroidism, delayed testosterone rise in puberty despite normal timing of testicular enlargement, adult macro-orchidism, and in some cases (65\%) deficiencies of PRL and/or GH [74, 75]. A delayed increase in dehydroepiandrosterone sulfate and delayed pubarche was recently described in a male with a novel hemizygous mutation [76]. A small proportion of heterozygous females show central hypothyroidism, PRL deficiency, and/or delayed menarche.

\section{Deficient anterior pituitary with variable immune deficiency (DAVID) syndrome}

Deficit in anterior pituitary gland function and common variable immune deficiency are 2 very different clinical presentations. Mutations in several genes have been associated with these 2 conditions, but until recently no gene has been associated with deficiencies in both systems in the same patient. In 2012, such patients were identified in France, and defined a novel disorder, called DAVID syndrome [77]. Chen et al. [78] reported mutations in the NFKB2 gene in 2 families from Utah with features consistent with DAVID syndrome. Since then de novo mutations near the C-terminus of NFKB2, have been reported in patients with similar phenotypes $[79,80]$. However, the precise mechanism how this factor may lead to endocrine deficits remains largely unclear.

\section{Axenfeld-Rieger syndrome}

Pitx2, a member of homeobox genes, is expressed in the stomodeum at E8, Rathke's pouch at E10.5 and pituitary anterior and intermediate lobes at E12.5. In humans, Pitx2 mutations are associated with Axenfeld-Rieger syndrome, which is characterized by anomalies in the ocular anterior compartment together with craniofacial dysmorphia, dental, cardiac, and umbilical anomalies [81].

\section{CHARGE syndrome and pituitary deficiencies}

CHARGE is an autosomal-dominant syndrome with a combination of eye coloboma, heart malformations, choanal atresia, retardation of growth and development, and genital and ear abnormalities. Gregory et al. first reported 2 novel CHD7 variants in patients with CHARGE syndrome and ectopic posterior pituitary: the first patient presented with central hypothyroidism, GH deficiency, and anterior pituitary hypoplasia associated with ectopic posterior pituitary and the second with GH, TSH, ACTH, LH/FSH deficiencies and the same MRI abnormalities [82].

\section{Non-synndromic Hypopituitarism}

Many cases of IGHD or GPHD are found without any concomitant abnormalities and are therefore not a part of a specific syndrome They are most commonly attributed to single gene mutations as listed in $>$ Table 1.

\section{Prop1}

PROP1 is a pituitary specific paired-like homeodomain transcription factor. It is located on chromosome $5 q 35$, consists of 3 highly conserved exons and 2 introns and encodes a protein of 226 amino acids. It is first expressed within Rathke's pouch at E10, peaks at E12 and then rapidly decreases until E15.5 when it disappears. Prop1 can act as both a transcriptional repressor (for Hesx 1 expression) and a transcriptional activator (for POU1F1).

Recessive mutations within PROP1 are the commonest genetic cause of CPHD both in sporadic (6.7\%) and familiar cases (48.5\%) [83-89]. Among 30 PROP1 variants causing CPHD reported so far, 2 are the most common - the deletion of 2 nucleotides (NM_0006261.4: c.[301_302delAG]; [301_302delAG] [90], and the deletion of one nucleotide (NM_0006261.4: c.[150delA]; [150delA]) which represent more than $90 \%$ of the mutated alleles in the Eastern European cohorts. Both lead to the production of an abnormally short protein that cannot function properly. Recessive PROP1 mutations are responsible for $\mathrm{GH}, \mathrm{TSH}, \mathrm{PRL}$ and gonadotrophin deficiencies, although the time of onset and the severity varies. Most patients present with early-onset GH deficiency and growth retardation; however, normal growth in early childhood has been reported in a patient who attained a normal final height without $\mathrm{GH}$ replacement therapy [91]. TSH deficiency is also highly variable and has been reported as the first presenting symptom in some cases [92], while others show delayed TSH deficiency [93].

Patients with PROP1 mutations present with normal ACTH/cortisol levels in early life but often demonstrate a cortisol deficiency later in their life, significantly correlated with increasing age [94, 95]. 
Although PROP1 is essential for the differentiation of gonadotrophs in fetal life, the spectrum of gonadotrophin deficiency ranges from hypogonadism presenting at birth with micropenis and undescended testes to complete lack of pubertal development or even spontaneous pubertal development with infertility $[93,95,96]$. The pituitary morphology is also highly variable; most patients have normal pituitary stalk and posterior lobe, with a small or normal anterior pituitary gland on MRI. However, in some cases, an enlarged anterior pituitary gland has been reported [90]with subsequent regression over time [97].

\section{Pit1/POU1F1}

Human POUIF1 (previously known as PIT-1) is a member of the POU family of transcription factors responsible for pituitary development. It has been localized to chromosome 3p11and encodes a 291 -amino acid protein with a molecular mass of $33 \mathrm{kD}$. The protein has 3 functional domains: a N-terminal trans-activating domain involved in protein-protein interactions, a POU-specific domain, and a POU-homeodomain involved in DNA binding and in interactions with transcriptional cofactors. It is expressed relatively late during pituitary development (e13.5) and its expression persists through postnatal life and adulthood. POUIF1 is important for regulation of the genes encoding $\mathrm{GH}, \mathrm{PRL}$ and TSHb. POUIF1 requires PROP11 expression and is able to interact with other transcription factors such as CREB-binding protein which interacts with GH promoter [98], PITX1 which activates the PRL and GH promoters [99], LHX3 which activate the POUIF1, TSHb and PRL promoters [11]. More than 30 POU1F1 mutations are reported to cause CPHD, which are associated usually with complete TSH, GH and PRL deficiencies. Gonadotroph and corticotroph axes remain usually functional. Brain MRI can be normal or show small anterior pituitary development. The commonest mutation is the dominant R271W mutation [100], which has been identified in several unrelated patients from different ethnic groups. No extra-pituitary anomaly has been reported up to date.

\section{Conclusions}

Congenital hypopituitarism may present either as isolated pituitary hormone or combined pituitary hormone deficiencies and can be a part of a syndrome comprising anomalies of the central nervous system or other organs. The same phenotype can be attributed to different gene mutations, while a given gene mutation can provoke different phenotypes. Moreover, a given gene mutation may give rise to different MRI findings of the pituitary region ranging from normal anterior pituitary to pituitary hypoplasia or even aplasia, while posterior pituitary may be either ectopic or eutopic. Therefore, a careful delineation of the clinical phenotype and the associated morphological findings is the crucial step in the investigation of the genetic background of cases of congenital hypopituitarism. So far, still many cases have not yet received their molecular identity and still many gene mutations or even gene- epigenetic interactions have to be unraveled in the future to explain as yet unclear cases of congenital hypopituitarism.

\section{Conflict of Interest}

The authors declare that they have no conflict of interest.

\section{References}

[1] Alatzoglou KS, Dattani MT. Genetic forms of hypopituitarism and their manifestation in the neonatal period. Early Hum Dev 2009; 85: 705-712

[2] Pfaeffle RW, Savage J], Hunter CS et al. Four novel mutations of the LHX3 gene cause combined pituitary hormone deficiencies with or without limited neck rotation. J Clin Endocrinol Metab 2007; 92: 1909-1919

[3] Savage J], Hunter CS, Clark-Sturm SL et al. Mutations in the LHX3 gene cause dysregulation of pituitary and neural target genes that reflect patient phenotypes. Gene 2007; 400: 44-51

[4] Bhangoo AP, Hunter CS, Savage J] et al. Clinical case seminar: A novel LHX3 mutation presenting as combined pituitary hormonal deficiency. J Clin Endocrinol Metab 2006; 91: 747-753

[5] Sloop KW, Parker GE, Hanna KR et al. LHX3 transcription factor mutations associated with combined pituitary hormone deficiency impair the activation of pituitary target genes. Gene 2001; 265: 61-69

[6] Howard PW, Maurer RA. A point mutation in the LIM domain of Lhx3 reduces activation of the glycoprotein hormone alpha-subunit promoter. J Biol Chem 2001; 276: 19020-19026

[7] Netchine I, Sobrier ML, Krude H et al. Mutations in LHX3 result in a new syndrome revealed by combined pituitary hormone deficiency. Nat Genet 2000; 25: 182-186

[8] Kristrom B, Zdunek AM, Rydh A et al. A novel mutation in the LIM homeobox 3 gene is responsible for combined pituitary hormone deficiency, hearing impairment, and vertebral malformations. J Clin Endocrinol Metab 2009; 94: 1154-1161

[9] Bonfig W, Krude H, Schmidt H. A novel mutation of LHX3 is associated with combined pituitary hormone deficiency including ACTH deficiency, sensorineural hearing loss, and short neck-A case report and review of the literature. Eur J Pediatr 2011; 170: 1017-1021

[10] Rajab A, Kelberman D, de Castro SC et al. Novel mutations in LHX3 are associated with hypopituitarism and sensorineural hearing loss. Hum Mol Genet 2008; 17: 2150-2159

[11] Sobrier ML, Brachet C, Vié-Luton MP et al. Symptomatic heterozygotes and prenatal diagnoses in a nonconsanguineous family with syndromic combined pituitary hormone deficiency resulting from two novel LHX3 mutations. J Clin Endocrinol Metab 2012; 97: E503-E509

[12] Jullien N, Philippon M, Quentien MH et al. Heterozygous LHX3 mutations may lead to a mild phenotype of combined pituitary hormone deficiency. Eur J Hum Genet 2018, doi:10.1038/ s41431-018-0264-6 [Epub ahead of print]

[13] Bechtold-Dalla Pozza S, Hiedl S, Roeb J et al. A recessive mutation resulting in a disabling amino acid substitution (T194R) in the LHX3 homeodomain causes combined pituitary hormone deficiency. Horm Res Paediatr 2012; 77: 41-51

[14] Pfaeffle RW, Hunter CS, Savage J] et al. Three novel missense mutations within the LHX4 gene are associated with variable pituitary hormone deficiencies. J Clin Endocrinol Metab 2008; 93: 1062-1071

[15] Tajima T, Yorifuji T, Ishizu K et al. A novel mutation (V101A) of the LHX4 gene in a Japanese patient with combined pituitary hormone deficiency. Exp Clin Endocrinol Diabetes 2010; 118: 405-409 
[16] Dateki S, Fukami M, Uematsu A et al. Mutation and gene copy number analyses of six pituitary transcription factor genes in 71 patients with combined pituitary hormone deficiency: Identification of a single patient with LHX4 deletion. J Clin Endocrinol Metab 2010; 95: 4043-4047

[17] Takagi M, Ishii T, Inokuchi M et al. Gradual loss of ACTH due to a novel mutation in LHX4: Comprehensive mutation screening in Japanese patients with congenital hypopituitarism. PLoS One 2012; 7: e46008

[18] Castinetti F, Saveanu A, Reynaud R et al. A novel dysfunctional LHX4 mutation with high phenotypical variability in patients with hypopituitarism. J Clin Endocrinol Metab 2008; 93: 2790-2799

[19] Rochette C, Jullien N, Saveanu A et al. Identifying the deleterious effect of rare LHX4 allelic variants, a challenging issue. PLoS One 2015; 10: e012664821

[20] Tajima T, Hattori T, Nakajima T et al. A novel missense mutation (P366T) of the LHX4 gene causes severe combined pituitary hormone deficiency with pituitary hypoplasia, ectopic posterior lobe and a poorly developed sella turcica. Endocr ] 2007; 54: 637-641

[21] Filges I, Bischof-Renner A, Röthlisberger B et al. Panhypopituitarism presenting as life-threatening heart failure caused by an inherited microdeletion in 1q25 including LHX4. Pediatrics 2012; 129: e529-e534

[22] Gregory LC, Humayun KN, Turton JP et al. Lethal form of congenital hypopituitarism associated with the first recessive LHX4 mutation. J Clin Endocrinol Metab 2015; 100: 2158-2164

[23] Cohen E, Maghnie M, Collot $\mathrm{N}$ et al. Contribution of LHX4 mutations to pituitary deficits in a cohort of 417 unrelated patients. J Clin Endocrinol Metab 2017; 102: 290-301

[24] Dattani MT, Martinez-Barbera JP, Thomas PQ et al. Mutations in the homeobox gene HESX1/Hesx1 associated with septo-optic dysplasia in human and mouse. Nat Genet 1998; 19: 125-133

[25] Thomas PQ, Dattani MT, Brickman JM et al. Heterozygous HESX1 mutations associated with isolated congenital pituitary hypoplasia and septo-optic dysplasia. Hum Mol Genet 2001; 10: 39-45

[26] Brickman JM, Clements M, Tyrell R et al. Molecular effects of novel mutations in Hesx1/HESX1 associated with human pituitary disorders. Development 2001; 128: 5189-5199

[27] Vivenza D, Godi M, Faienza MF et al. A novel HESX1 splice mutation causes isolated $\mathrm{GH}$ deficiency by interfering with mRNA processing. Eur J Endocrinol 2011; 164: 705-713

[28] Takagi M, Takahashi M, Ohtsu Y et al. A novel mutation in HESX1 causes combined pituitary hormone deficiency without septo optic dysplasia phenotypes. Endocr J 2016; 63: 405-410

[29] Fang Q, Benedetti AF, Ma Q et al. HESX1 mutations in patients with congenital hypopituitarism: Variable phenotypes with the same genotype. Clin Endocrinol (Oxf) 2016; 85: 408-414

[30] McNay DE, Turton JP, Kelberman D et al. HESX1 mutations are an uncommon cause of septooptic dysplasia and hypopituitarism. J Clin Endocrinol Metab 2007; 92: 691-697

[31] Kelberman D, Rizzoti K, Avilion A et al. Mutations within Sox2/SOX2 are associated with abnormalities in the hypothalamo-pituitary-gonadal axis in mice and humans. J Clin Invest 2006; 116: 2442-2455

[32] Kelberman D, de Castro SC, Huang S et al. SOX2 plays a critical role in the pituitary, forebrain, and eye during human embryonic development. J Clin Endocrinol Metab 2008; 93: 1865-1873

[33] Sato N, Kamachi Y, Kondoh $\mathrm{H}$ et al. Hypogonadotropic hypogonadism in an adult female with a heterozygous hypomorphic mutation of SOX2. Eur J Endocrinol 2007; 156: 167-171

[34] Stark Z, Storen R, Bennetts B et al. Isolated hypogonadotropic hypogonadism with SOX2 mutation and anophthalmia/microphthalmia in offspring. Eur J Hum Genet 2011; 19: 753-756
[35] Errichiello E, Gorgone C, Giuliano L et al. SOX2: Not always eye malformations. Severe genital but no major ocular anomalies in a female patient with the recurrent c.70del20 variant. Eur J Med Genet 2018; 61: 335-340

[36] Macchiaroli A, Kelberman D, Auriemma RS et al. A novel heterozygous SOX2 mutation causing congenital bilateral anophthalmia, hypogonadotropic hypogonadism and growth hormone deficiency. Gene 2014; 534: 282-285

[37] Alatzoglou KS, Andoniadou CL, Kelberman D et al. SOX2 haploinsufficiency is associated with slow progressing hypothalamo-pituitary tumours. Hum Mutat 2011; 32: 1376-1380

[38] Takagi M, Ishii T, Torii C et al. A novel mutation in SOX3 polyalanine tract: A case of Kabuki syndrome with combined pituitary hormone deficiency harboring double mutations in MLL2 and SOX3. Pituitary 2014; 17: 569-574

[39] Laumonnier F, Ronce N, Hamel BC et al. Transcription factor SOX3 is involved in X-linked mental retardation with growth hormone deficiency. Am J Hum Genet 2002; 71: 1450-1455

[40] Stankiewicz P, Thiele H, Schlicker M. Duplication of Xq26.2-q27.1, including SOX3, in a mother and daughter with short stature and dyslalia. Am J Med Genet A 2005; 138: 11-17

[41] Dateki S, Kosaka K, Hasegawa K et al. Heterozygous orthodenticle homeobox 2 mutations are associated with variable pituitary phenotype. J Clin Endocrinol Metab 2010; 95: 756-764

[42] Shimada A, Takagi M, Nagashima Y et al. A novel mutation in OTX2 Causes combined pituitary hormone deficiency, bilateral microphthalmia, and agenesis of the left internal carotid artery. Horm Res Paediatr 2016; 86: 62-69

[43] Jones GE, Robertson L, Warman P et al. 14q22.3 Microdeletion encompassing OTX2 in a five-generation family with microphthalmia, pituitary abnormalities, and intellectual disability. Ophthalmic Genet 2016; 37: 352-353

[44] Lonero A, Delvecchio M, Primignani P et al. OTX2 gene frameshift mutation in a child with microphthalmia, ectopic pituitary and growth hormone deficiency. J Pediatr Endocrinol Metab 2016; 29: 603-605

[45] Diaczok D, Romero C, Zunich J et al. A novel dominant negative mutation of OTX2 associated with combined pituitary hormone deficiency. J Clin Endocrinol Metab 2008; 93: 4351-4359

[46] Dateki S, Fukami M, Sato $N$ et al. OTX2 mutation in a patient with anophthalmia, short stature, and partial growth hormone deficiency: Functional studies using the IRBP, HESX1, and POU1F1 promoters. J Clin Endocrinol Metab 2008; 93: 3697-3702

[47] Ashkenazi-Hoffnung L, Lebenthal Y, Wyatt AW et al. A novel loss-of-function mutation in OTX2 in a patient with anophthalmia and isolated growth hormone deficiency. Hum Genet 2010; 127: 721-729

[48] Henderson RH, Williamson KA, Kennedy JS et al. A rare de novo nonsense mutation in OTX2 causes early onset retinal dystrophy and pituitary dysfunction. Mol Vis 2009; 15: 2442-2447

[49] Gorbenko Del Blanco D, Romero C], Diaczok D et al. A novel OTX2 mutation in a patient with combined pituitary hormone deficiency, pituitary malformation, and an underdeveloped left optic nerve. Eur J Endocrinol 2012; 167: 441-452

[50] Kioussi C, O'Connell S, St-Onge L et al. Pax6 is essential for establishing ventral-dorsal cell boundaries in pituitary gland development. Proc Natl Acad Sci U S A 1999; 96: 14378-14382

[51] Hergott-Faure L, Borot $S$, Kleinclauss $C$ et al. Pituitary function and glucose tolerance in a family with a PAX6 mutation. Ann Endocrinol (Paris) 2012; 73: 510-514

[52] Shimo N, Yasuda T, Kitamura T et al. Aniridia with a heterozygous PAX6 mutation in which the pituitary function was partially impaired. Intern Med 2014; 53: 39-42 
[53] Takagi M, Nagasaki K, Fujiwara I et al. Heterozygous defects in PAX6 gene and congenital hypopituitarism. Eur J Endocrinol 2015; 172: 37-45

[54] Bakrania P, Efthymiou M, Klein JC et al. Mutations in BMP4 cause eye, brain, and digit developmental anomalies: Overlap between the BMP4 and hedgehog signaling pathways. Am J Hum Genet 2008; 82: 304-319

[55] Breitfeld J, Martens S, Klammt J et al. Genetic analyses of bone morphogenetic protein 2, 4 and 7 in congenital combined pituitary hormone deficiency. BMC Endocr Disord 2013; 13: 56

[56] Koika V, Varnavas P, Valavani $\mathrm{H}$ et al. Comparative functional analysis of two fibroblast growth factor receptor 1 (FGFR1) mutations affecting the same residue (R254W and R254Q) in isolated hypogonadotropic hypogonadism (IHH). Gene 2013; 516: 146-151

[57] Raivio T, Avbelj M, McCabe M] et al. Genetic overlap in Kallmann syndrome, combined pituitary hormone deficiency, and septo-optic dysplasia. J Clin Endocrinol Metab 2012; 97: E694-E699

[58] Fukami M, Iso M, Sato $\mathrm{N}$ et al. T.Submicroscopic deletion involving the fibroblast growth factor receptor 1 gene in a patient with combined pituitary hormone deficiency. Endocr J 2013; 60: 1013-1020

[59] Webb EA, AIMutair A, Kelberman D et al. ARNT2 mutation causes hypopituitarism, post-natal microcephaly, visual and renal anomalies. Brain 2013; 136 (Pt 10): 3096-3105

[60] Paulo SS, Fernandes-Rosa FL, Turatti W et al. Sonic Hedgehog mutations are not a common cause of congenital hypopituitarism in the absence of complex midline cerebral defects. Clin Endocrinol (Oxf) 2015; 82: 562-569

[61] Roessler E, Du YZ, Mullor JL et al. Loss-of-function mutations in the human GLI2 gene are associated with pituitary anomalies and holoprosencephaly-like features. Proc Natl Acad Sci USA 2003; 100: 13424-13429

[62] Roessler E, Ermilov AN, Grange DK et al. A previously unidentified amino-terminal domain regulates transcriptional activity of wild-type and disease-associated human GLI2. Hum Mol Genet 2005; 14: 2181-2188

[63] Bear KA, Solomon BD, Antonini S et al. Pathogenic mutations in GLI2 cause a specific phenotype that is distinct from holoprosencephaly. J Med Genet 2014; 51: 413-418

[64] Bertolacini CD, Ribeiro-Bicudo LA, Petrin A et al. Clinical findings in patients with GLI2 mutations--phenotypic variability. Clin Genet 2012; 81: 70-75

[65] Franca MM, Jorge AA, Carvalho LR et al. Novel heterozygous nonsense GLI2 mutations in patients with hypopituitarism and ectopic posterior pituitary lobe without holoprosencephaly. J Clin Endocrinol Metab 2010; 95: E384-E391

[66] Gregory LC, Gaston-Massuet C, Andoniadou CL et al. The role of the sonic hedgehog signalling pathway in patients with midline defects and congenital hypopituitarism. Clin Endocrinol (Oxf) 2015; 82: 728-738

[67] McCabe M], Gaston-Massuet C, Tziaferi V et al. Novel FGF8 mutations associated with recessive holoprosencephaly, craniofacial defects, and hypothalamo-pituitary dysfunction. J Clin Endocrinol Metab 2011; 96: E1709-E1718

[68] Tatsi C, Sertedaki A, Voutetakis A et al. Pituitary stalk interruption syndrome and isolated pituitary hypoplasia may be caused by mutations in holoprosencephaly-related genes. J Clin Endocrinol Metab 2013; 98: E779-E784

[69] Reynaud R, Jayakody SA, Monnier C et al. PROKR2 variants in multiple hypopituitarism with pituitary stalk interruption. J Clin Endocrinol Metab 2012; 97: E1068-E1073

[70] Reynaud R, Albarel F, Saveanu A et al. Pituitary stalk interruption syndrome in 83 patients: Novel HESX1 mutation and severe hormonal prognosis in malformative forms. Eur J Endocrinol 2011; 164: 457-465
[71] McCabe M], Gaston-Massuet C, Gregory LC et al. Variations in PROKR2, but not PROK2, are associated with hypopituitarism and septo-optic dysplasia. J Clin Endocrinol Metab 2013; 98: E547-E557

[72] Correa FA, Trarbach EB, Tusset C et al. FGFR1 and PROKR2 rare variants found in patients with combined pituitary hormone deficiencies. Endocr Connect 2015; 4: 100-107

[73] Karaca E, Buyukkaya R, Pehlivan D et al. Whole-exome sequencing identifies homozygous GPR161 mutation in a family with pituitary stalk interruption syndrome. J Clin Endocrinol Metab 2015; 100: E140-E147

[74] Sun Y, Bak B, Schoenmakers N et al. Loss-of-function mutations in IGSF1 cause an X-linked syndrome of central hypothyroidism and testicular enlargement. Nat Genet 2012; 44: 1375-1381

[75] Joustra SD, Schoenmakers N, Persani L et al. ASThe IGSF1 deficiency syndrome: Characteristics of male and female patients. J Clin Endocrinol Metab 2013; 98: 4942-4952

[76] Van Hulle S, Craen M, Callewaert B et al. Adrenarche may be an Additional Feature of Immunoglobulin Super Family Member 1 Deficiency Syndrome. J Clin Res Pediatr Endocrinol 2016; 8: 86-91

[77] Quentien MH, Delemer B, Papadimitriou DT et al. Deficit in anterior pituitary function and variable immune deficiency (DAVID) in children presenting with adrenocorticotropin deficiency and severe infections. J Clin Endocrinol Metab 2012; 97: E121-E128

[78] Chen K, Coonrod EM, Kumánovics A et al. Germline mutations in NFKB2 implicate the noncanonical NF-kappaB pathway in the pathogenesis of common variable immunodeficiency. Am J Hum Genet 2013; 93: 812-824

[79] Lee CE, Fulcher DA, Whittle B et al. Autosomal-dominant B-cell deficiency with alopecia due to a mutation in NFKB2 that results in nonprocessable p100. Blood 2014; 124: 2964-2672

[80] Liu Y, Hanson S, Gurugama P et al. Novel NFKB2 mutation in early-onset CVID. J Clin Immunol 2014; 34: 686-690

[81] Hassed S], Li S, Xu W et al. Mutation in PITX2 in a Patient with Axenfeld-Rieger Syndrome. Mol Syndromol 2017; 8: 107-109

[82] Gregory LC, Gevers EF, Baker J et al. Structural pituitary abnormalities associated with CHARGE syndrome. J Clin Endocrinol Metab 2013; 98 : E737-E743

[83] De Rienzo F, Mellone S, Bellone $S$ et al. Frequency of genetic defects in combined pituitary hormone deficiency: A systematic review and analysis of a multicentre Italian cohort. Clin Endocrinol (Oxf) 2015; 83: $849-860$

[84] Nose O, Tatsumi K, Nakano Y et al. Congenital combined pituitary hormone deficiency attributable to a novel PROP1 mutation (467insT). J Pediatr Endocrinol Metab 2006; 19: 491-498

[85] Abrao MG, Leite MV, Carvalho LR et al. Combined pituitary hormone deficiency (CPHD) due to a complete PROP1 deletion. Clin Endocrinol (Oxf) 2006; 65: 294-300

[86] Lebl J, Vosáhlo J, Pfaeffle RW. Auxological and endocrine phenotype in a population-based cohort of patients with PROP1 gene defects. Eur J Endocrinol 2005; 153: 389-396

[87] Tatsumi KI, Kikuchi K, Tsumura K et al. A novel PROP1 gene mutation (157delA) in Japanese siblings with combined anterior pituitary hormone deficiency. Clin Endocrinol (Oxf) 2004; 61: 635-640

[88] Reynaud R, Chadli-Chaieb M, Vallette-Kasic S et al. A familial form of congenital hypopituitarism due to a PROP1 mutation in a large kindred: Phenotypic and in vitro functional studies. J Clin Endocrinol Metab 2004; 89: 5779-5786

[89] Paracchini R, Giordano M, Corrias A et al. Two new PROP1 gene mutations responsible for compound pituitary hormone deficiency. Clin Genet 2003; 64: 142-147

[90] Wu W, Cogan JD, Pfäffle RW et al. Mutations in PROP1 cause familial combined pituitary hormone deficiency. Nat Genet 1998; 18: 147-149 
[91] Arroyo A, Pernasetti F, Vasilyev VV. A unique case of combined pituitary hormone deficiency caused by a PROP1 gene mutation (R120C) associated with normal height and absent puberty. Clin Endocrinol (Oxf) 2002; 57: 283-291

[92] Voutetakis A, Maniati-Christidi M, Kanaka-Gantenbein C et al. A Prolonged jaundice and hypothyroidism as the presenting symptoms in a neonate with a novel Prop1 gene mutation (Q83X). Eur J Endocrinol 2004; 150: 257-264

[93] Deladoey J, Büyükgebiz A, Kuhlmann BV et al. "Hot spot" in the PROP1 gene responsible for combined pituitary hormone deficiency. J Clin Endocrinol Metab 1999; 84: p 1645-1650

[94] Asteria C, Oliveira JH, Abucham J et al. Central hypocortisolism as part of combined pituitary hormone deficiency due to mutations of PROP-1 gene. Eur J Endocrinol 2000; 143: 347-352

[95] Pernasetti F, Toledo SP, Vasilyev VV et al. Impaired adrenocorticotropin-adrenal axis in combined pituitary hormone deficiency caused by a two-base pair deletion (301-302delAG) in the prophet of Pit-1 gene. J Clin Endocrinol Metab 2000; 85: 390-397
[96] Vallette-Kasic S, Barlier A, Teinturier C et al. PROP1 gene screening in patients with multiple pituitary hormone deficiency reveals two sites of hypermutability and a high incidence of corticotroph deficiency. J Clin Endocrinol Metab 2001; 86: 4529-4535

[97] Voutetakis A, Sertedaki A, Livadas S et al. Pituitary size fluctuation in long-term MR studies of PROP1 deficient patients: A persistent pathophysiological mechanism? J Endocrinol Invest 2006; 29: 462-466

[98] Romero C], Pine-Twaddell E, Sima DI et al. Insulin-like growth factor 1 mediates negative feedback to somatotroph $\mathrm{GH}$ expression via POU1F1/CREB binding protein interactions. Mol Cell Biol 2012; 32: 4258-4569

[99] Szeto DP, Ryan AK, O'Connell SM et al. P-OTX: A PIT-1-interacting homeodomain factor expressed during anterior pituitary gland development. Proc Natl Acad Sci USA 1996; 93: 7706-7710

[100] Cohen LE, Wondisford FE, Salvatoni A et al. A "hot spot" in the Pit-1 gene responsible for combined pituitary hormone deficiency: Clinical and molecular correlates. J Clin Endocrinol Metab 1995; 80: 679-684 